Research Article

\title{
Evaluation of effect of highly standardized aqueous extract of roots and leaves of Withania somnifera on cold pressor test induced cardiovascular changes in healthy human subjects
}

\author{
Raveendranath Pilli, Niranjan Koilagundla, Ramakanth GSH*, Usharani Pingali
}

\begin{abstract}
Department of Clinical
Pharmacology and Therapeutics, Nizam's Institute of Medical

Sciences, Punjagutta,

Hyderabad, Telangana, India

Received: 09 March 2016

Accepted: 15 April 2016

*Correspondence to:

Dr. Ramakanth GSH,

Email: grkclinpharma

@gmail.com

Copyright: () the author(s), publisher and licensee Medip Academy. This is an openaccess article distributed under the terms of the Creative Commons Attribution NonCommercial License, which permits unrestricted noncommercial use, distribution, and reproduction in any medium, provided the original work is properly cited.
\end{abstract}

\begin{abstract}
Background: Stress is an important cardiovascular risk factor. Cold pressor test (CPT) is a simple, validated, non-invasive test used to measure stress induced changes in cardiovascular parameters. The objective of this study was to evaluate effect of Withania somnifera extract on cold pressor stress test induced changes on cardiovascular parameters and aortic wave reflections in healthy human subjects.

Methods: This was a double-blind, placebo controlled, crossover study. Participants were randomized to receive either two capsules of Withania somnifera extract $250 \mathrm{mg}$ or two capsules of placebo twice daily for 14 days. Pharmacodynamic parameters heart rate, aortic pressure, augmentation index (AIx), subendocardial viability ratio (SEVR), radial and aortic blood pressure (BP) were recorded before and after CPT at baseline and at end of treatment. After washout period of 10 days, subjects crossed over to other treatment group and same procedure was repeated. Safety assessments were done at baseline and at end of treatment.

Results: A total of 20 volunteers completed the study. Compared with baseline and placebo, Withania somnifera extract produced a significant decrease in mean percent change of arterial stiffness indices (AIx, radial and aortic BP). SEVR with CPT increased, however it was non-significant compared to baseline and placebo. Both treatments were well-tolerated and no serious adverse events were reported.

Conclusions: Withania somnifera extract showed a significant decrease in cold pressor stress test induced changes on aortic wave reflections, suggesting its beneficial effects in reducing stress induced cardiovascular changes. However, further clinical studies are warranted to evaluate these effects in patients with cardiovascular and other associated diseases.
\end{abstract}

Keywords: Augmentation index, Cardiovascular disease, Cold pressor test, Withania somnifera

\section{INTRODUCTION}

The maintenance of life is critically dependent on keeping the internal milieu constant in the face of a changing environment. "This is known as "homeostasis.", According to Selye, "stress" represents the effects of anything that seriously threatens homeostasis. Severe, prolonged stress responses might lead to tissue damage and disease. ${ }^{3}$ Allostasis refers to the maintenance of homeostasis through the constant adjustment and balancing of hypothalamic pituitary adrenal (HPA) axis and sympathoadrenal medullary (SAM) pathways in the process of adapting to challenge. ${ }^{4-6}$

The relationship between stress and cardiovascular disease is complex. Type A pattern individuals, who are generally stressed out, tend to be associated with a greater cardiovascular risk due to increased sympathetic activity and enhanced catecholamine responses to stress. ${ }^{7}$ Free radicals generated by stress cause oxidative stress 
damage to cardiovascular tissues leading to imbalance between oxidant/antioxidant systems. $^{8}$ The existing evidence support the view that oxidative stress may play a crucial role in different types of cardiovascular diseases and that the antioxidant therapy may prove beneficial in combating these problems. ${ }^{9}$

Antioxidants play an important protective role against reactive oxygen species. Withania somnifera (family Solanaceae), also called as "Ashwagandha", is used widely in traditional medicine for its anti-inflammatory, anti-tumour, anti-stress, anti-oxidant, immunomodulatory, haemopoetic and rejuvenating properties. ${ }^{10}$ The anti-oxidative property of WS mainly by increasing the free radical scavenging enzymes like superoxide dismutase, catalase and glutathione peroxidise levels. ${ }^{11}$ Augmentation of endogenous antioxidants, maintenance of the myocardial antioxidant status and significant restoration of most of the altered haemodynamic parameters may contribute to its cardio protective effect. ${ }^{12}$

Acute cold stress contributes to elevations in blood pressure and heart rate. Studies report that a sudden exposure to the cold can increase the blood pressure of humans by $20 \mathrm{mmHg}$, especially when there exists cold induced pain at the same time. ${ }^{13,14}$ The effects of cold induced stress on cardiovascular changes in normal healthy subjects can be evaluated by cold pressor test, which is a simple, non-invasive and validated test for sympathetic activation. $^{15}$

The present study was hence undertaken to evaluate the effect of Withania somnifera on cold pressor stress test induced changes on cardiovascular parameters and aortic wave reflections in healthy human subjects.

The objective of this study was to evaluate the effect of Withania somnifera extract on cold pressor stress test induced changes on cardiovascular parameters and aortic wave reflections in healthy human subjects.

\section{METHODS}

This was a prospective, randomized, double blind multidose, cross-over, placebo controlled study conducted after approval of the Institutional Ethics Committee of Nizam's Institute of Medical Sciences (NIMS), Hyderabad, India. All subjects gave written informed consent prior to participation in the study. The cold pressor stress test model equipment used in the present study was designed and validated by the department of Clinical Pharmacology and Therapeutics, NIMS, Hyderabad. $^{16}$

Twenty six healthy male subjects, aged 20-35 years were screened for their eligibility to participate in the study with complete medical history, physical examination, hematological and biochemical screening, electrocardiogram and chest X-ray. History of smoking and drug abuse was excluded. The subjects were excluded from study if there was any evidence of physical illness, drug abuse or abnormal laboratory parameters. Eligible subjects were trained on the test procedure on two prior occasions to make them familiar with the testing device and test procedure. All the recordings were carried out in the morning between 7.30 am and 10:00 am after a light breakfast.

The study medications included capsules of Sensoril® (250 mg strength) and placebo. Each Sensoril® $250 \mathrm{mg}$ capsule consisted of highly standardized aqueous extract of roots and leaves of Withania somnifera (Sensoril®) containing not less than $10 \%$ withanolide glycosides, not less than $32 \%$ oligosaccharides and not more than $0.5 \%$ of Withaferin-A. Each placebo capsule contained microcrystalline cellulose $(49.7 \% \mathrm{w} / \mathrm{w})$, lactose $(49.5 \%)$ and magnesium stearate $(0.69 \%$ w/w). Both study medications were supplied by Natreon, Inc. USA.

\section{Study procedure}

The study used a double blind placebo controlled crossover design, with participants randomized to receive either two capsules of W.somnifera $250 \mathrm{mg}$ twice a day or two capsules of placebo twice a day for 14 days in Run I. Subjects arrived at the study site following an overnight fast and abstinence of caffeine containing beverages and alcohol for 12 hours. Before initiating the test procedure, the subjects were rested in a supine position for 20 minutes in a quiet, temperature-controlled $\left(26^{\circ} \pm 1^{\circ} \mathrm{C}\right)$ room. Subjects were asked to breathe normally and to remain still during cardiovascular measurements. They were permitted to listen to music and to read, except during the periods of cardiovascular measurements. The test measurements were performed at baseline and at the end of 14 days. All the measurements were recorded 3 hours post drug administration. The baseline arterial stiffness was recorded with Sphygmocor, after which cold pressor test (CPT) was performed. The arterial stiffness was again recorded within 2 minutes of performing CPT.

\section{Recording of vital parameters}

Brachial BP and heart rate were measured with an automated digital BP monitor (OMRAN, SEM-1) and a mean of three readings was taken. All readings were taken with cuff placed on the subject's non-dominant arm positioned at heart level with the forearm resting on a table.

\section{Cold pressor test $(\mathrm{CPT})$}

Cold pressor test is a potent stimulus for eliciting large elevations in blood pressure. The recording was performed in a temperature controlled room at $24^{\circ} \mathrm{C}$. After 10 minutes of rest, subject's BP was recorded. Then the subject's non-dominant hand was immersed till the wrist in the water bath maintained at $35^{\circ} \mathrm{C}$ for 2 minutes. 
15 seconds before the end of this 2 minute period, a pressure of $20 \mathrm{~mm}$ less than the normal diastolic pressure of that subject was applied using BP cuff on the lower part of non-dominant hand. Immediately after applying the pressure the subject was asked to immerse his nondominant hand till the wrist in to the cold water bath maintained at $4-5^{\circ} \mathrm{C}$, till he was able to sense unbearable pain. The subject was then asked immerse his hand again in water bath maintained at $35^{\circ} \mathrm{C}$ for 1 minute for normalization of temperature. ${ }^{16}$

\section{Measurement of wave reflection indices}

Arterial stiffness was measured by using a validated, commercially available system (SphygmoCor; AtCor Medical, Australia) that employs the principle of applanation tonometry and appropriate acquisition and analysis software for non-invasive recording and analysis of the arterial pulse. ${ }^{17-19}$ Augmentation index (AIx) and augmented pressure of the central (aortic) pressure waveforms were measured as indices of wave reflections. The AIx (defined as augmented pressure divided by pulse pressure and expressed as a percentage) is a composite measure of the magnitude of wave reflections and arterial stiffness, which affects timing of wave reflections. Because the augmentation index is influenced by changes in heart rate (HR), it was also accordingly corrected. The central (aortic) arterial pressure was derived from radial artery recordings, with the use of a generalized transfer function that has been shown to give an accurate estimate of the central arterial pressure waveform and its characteristics. Wave forms of radial pressure were calibrated according to sphygmomanometric systolic and diastolic pressure measured in the brachial artery because there is practically negligible pressure pulse amplification between the brachial and the radial artery. The subendocardial viability index was calculated as the ratio of the integral of diastolic pressure and time to the integral of systolic pressure and time. The subendocardial viability index, an indicator of myocardial workload and perfusion (O2 supply vs. demand) was calculated as the ratio of the integral of diastolic pressure and time to the integral of systolic pressure and time. ${ }^{20}$

After the baseline test measurements, the subjects were discharged with study medications for 14 days and were instructed to take 2 capsules twice daily with $240 \mathrm{ml}$ of water. The same test procedure was again repeated after 14 days of treatment to obtain post treatment values. A washout period of 10 days was given between the treatments. Subjects were then crossed over to receive the second formulation of 2 capsules twice daily for 14 days for run II. All the test procedures described for run I were repeated pre and post treatment.

\section{Statistical analysis}

The study has been carried out in 26 healthy volunteers as a pilot study. Two-way ANOVA and paired t-test were used for the analysis of study parameters. A $p<0.05$ was considered to be statistically significant. All statistical analyses were performed using Graphpad Prism 5, Sandiego, CA, USA.

\section{RESULTS}

A total of twenty six male subjects were screened, out of whom twenty eligible male subjects were randomized into the study to receive the study medications in a crossover design. All the randomized subjects completed the study and were evaluated for cardiovascular measurements. Mean age, height and weight of the randomized subjects were $24.89 \pm 4.90$ years, $170 \pm 4.14 \mathrm{~cm}, 64.63 \pm 5.29 \mathrm{~kg}$ respectively.

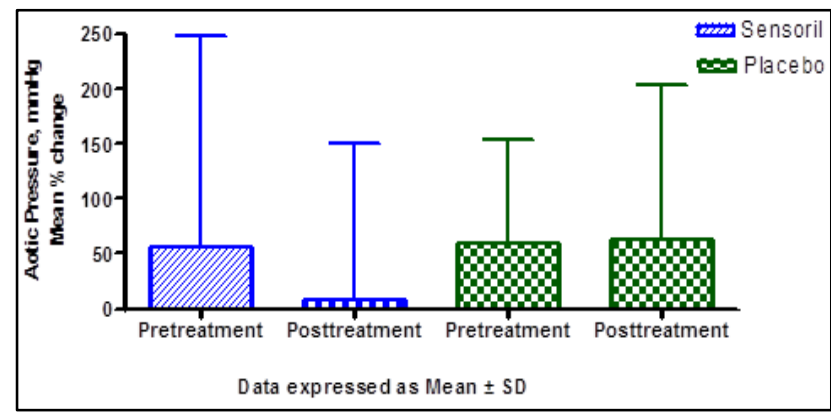

Figure 1: Mean \% change in aortic pressure induced by cold presssor test Withania somnifera and placebo (n-20).

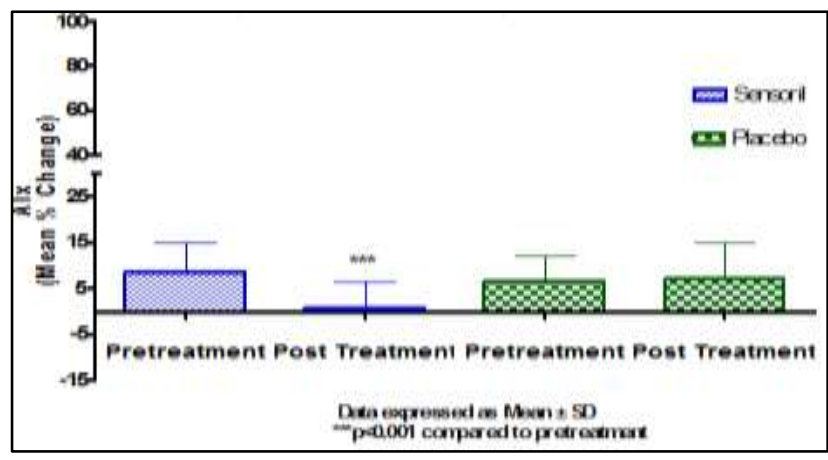

Figure 2: Mean \% change in augmentation index induced by cold pressor test Withania somnifera and placebo (n-20).

\section{Effect of cold pressor test on wave reflections}

The results of effect of cold pressor test on wave reflections are shown in (Table 1). W. somnifera produced a statistically significant decrease in aortic pressure $(\mathrm{p}<0.05)$ (Figure 1), augmentation index $(\mathrm{p}<0.001)$ (Figure 2), radial systolic blood pressure $(\mathrm{p}<0.05)$, aortic systolic blood pressure $(\mathrm{p}<0.01)$, radial and aortic mean blood pressures $(\mathrm{p}<0.05)$ and radial pulse pressure $(p<0.05)$, compared to baseline. An increase in heart rate and SEVR were observed, which were not statistically significant $(\mathrm{p}>0.05)$. Also, a non- significant decrease in radial and aortic diastolic blood pressures and aortic pulse 
pressure were observed $(p>0.05)$. When compared with placebo, statistically significant differences $(\mathrm{p}<0.05)$ were observed with $W$. somnifera in aortic pressure, augmentation index, radial and aortic systolic blood pressures, radial and aortic diastolic blood pressures, radial and aortic mean blood pressures and radial pulse pressure. No significant differences were observed in heart rate, SEVR and aortic pulse pressure ( $>0.05)$. All subjects tolerated both treatments well and none of the subjects discontinued the study due to adverse events. Safety laboratory parameters were within normal values.

Table 1: Effects of Withania somnifera and placebo on cold pressor induced changes in waveform reflections, (Data are expressed as the mean \pm SD).

\begin{tabular}{|c|c|c|c|c|c|c|c|c|c|}
\hline & & \multicolumn{4}{|c|}{ Withania somnifera } & \multicolumn{4}{|c|}{ Placebo } \\
\hline & & \multicolumn{3}{|c|}{ Pre treatment } & \multirow{2}{*}{$\begin{array}{c}\text { Post treatment } \\
\text { Within } 2 \\
\text { minutes of } \\
\text { hand } \\
\text { immersion }\end{array}$} & \multicolumn{2}{|c|}{ Pre treatment } & \multicolumn{2}{|c|}{ Post treatment } \\
\hline & & $\begin{array}{l}\text { Baseline } \\
\text { (Before CPT) }\end{array}$ & $\begin{array}{l}\text { Within } 2 \\
\text { minutes of } \\
\text { hand } \\
\text { immersion }\end{array}$ & $\begin{array}{l}\text { Baseline } \\
\text { (Before CPT) }\end{array}$ & & $\begin{array}{l}\text { Baseline } \\
\text { (Before } \\
\text { CPT) }\end{array}$ & $\begin{array}{l}\text { Within } 2 \\
\text { minutes of } \\
\text { hand } \\
\text { immersion }\end{array}$ & $\begin{array}{l}\text { Baseline } \\
\text { (Before } \\
\text { CPT) }\end{array}$ & $\begin{array}{l}\text { Within } 2 \\
\text { minutes of } \\
\text { hand } \\
\text { immersion }\end{array}$ \\
\hline HR (bpm) & & $71 \pm 7.15$ & $68 \pm 6.79$ & $71 \pm 6.28$ & $70 \pm 6.96^{\mathrm{NS}}$ & $70 \pm 4.94$ & $69 \pm 3.52$ & $70 \pm 4.08$ & $69 \pm 4.60$ \\
\hline $\mathrm{AP}(\mathrm{mmH}$ & & $2.9 \pm 3.72$ & $6.35 \pm 3.99$ & $2.27 \pm 3.20$ & $3.21 \pm 3.01 * \#$ & $3.80 \pm 3.90$ & $5.95 \pm 3.72$ & $4.25 \pm 4.16$ & $7.45 \pm 4.41$ \\
\hline AIx $(\%)$ & & $114.11 \pm 18.02$ & $124 \pm 21.86$ & $109.86 \pm 14.34$ & $110.54 \pm 14.26^{* * *, \#}$ & $116 \pm 19.75$ & $123 \pm 19.26$ & $\begin{array}{l}117.25 \pm \\
19.84\end{array}$ & $125 \pm 19.14$ \\
\hline SEVR $(\%)$ & & $147.5 \pm 19.22$ & $149.37 \pm 16.21$ & $144 \pm 19.89$ & $151 \pm 18.66^{\mathrm{NS}}$ & $144 \pm 16.68$ & $148 \pm 13.55$ & $143 \pm 14.27$ & $147 \pm 15.3$ \\
\hline SBP & \multirow{4}{*}{$\begin{array}{l}\mathrm{Ra} \\
\text { dia } \\
1\end{array}$} & $113 \pm 4.41$ & $122 \pm 7.11$ & $112 \pm 4.15$ & $114 \pm 4.70^{*, \#}$ & $112.9 \pm 4.02$ & $120 \pm 5.33$ & $114 \pm 2.97$ & $122 \pm 4.78$ \\
\hline DBP & & $69 \pm 5.06$ & $72 \pm 8.16$ & $70 \pm 3.66$ & $71 \pm 4.81^{\mathrm{NS}, \#}$ & $71.2 \pm 4.42$ & $74 \pm 4.08$ & $71 \pm 3.64$ & $73.9 \pm 3.27$ \\
\hline MBP & & $85 \pm 4.66$ & $89 \pm 7.92$ & $83 \pm 3.22$ & $85 \pm 4.62 *, \#$ & $85 \pm 3.74$ & $90 \pm 4.00$ & $85 \pm 2.96$ & $90 \pm 3.13$ \\
\hline PP & & $44 \pm 5.20$ & $50 \pm 8.18$ & $42 \pm 5.24$ & $43 \pm 4.55^{* \# \#}$ & $42 \pm 4.46$ & $46 \pm 4.55$ & $43 \pm 3.69$ & $48 \pm 4.72$ \\
\hline SBP & \multirow{4}{*}{$\begin{array}{l}\text { Ao } \\
\mathrm{rti} \\
\mathrm{c}\end{array}$} & $98 \pm 4.76$ & $106 \pm 8.46$ & $98 \pm 3.77$ & $99 \pm 5.05^{* * * \#}$ & $98 \pm 4.63$ & $104 \pm 5.25$ & $99 \pm 4.87$ & $106 \pm 5.35$ \\
\hline DBP & & $69.41 \pm 5.52$ & $72.95 \pm 8.0$ & $69 \pm 4.27$ & $70 \pm 5.16^{\mathrm{NS}, \#}$ & $70 \pm 4.75$ & $73 \pm 5.55$ & $71 \pm 3.58$ & $74 \pm 3.55$ \\
\hline MBP & & $81 \pm 5.98$ & $87 \pm 8.87$ & $81 \pm 5.07$ & $81 \pm 4.91^{*, \#}$ & $79 \pm 3.65$ & $84 \pm 4.44$ & $80 \pm 2.99$ & $85 \pm 2.93$ \\
\hline $\mathrm{PP}$ & & $28 \pm 4.67$ & $32 \pm 6.11$ & $29 \pm 3.71$ & $30 \pm 4.13^{\mathrm{NS}}$ & $28 \pm 6.29$ & $31 \pm 6.72$ & $28 \pm 5.81$ & $32 \pm 6.49$ \\
\hline
\end{tabular}

HR: Heart rate; AP: Aortic Pressure; AIx: Augmentation index; SEVR: Subendocardial viability ratio; SBP: Systolic blood pressure; DBP: Diastolic blood pressure ; MBP: Mean blood pressure; PP: Pulse pressure; $* \mathrm{p}<0.05$, compared to baseline; $* * \mathrm{p}<0.01$, compared to baseline; $* * * \mathrm{p}<0.001$, compared to baseline; NS-not significant, compared to baseline; \# $\mathrm{p}<0.05$, compared to placebo.

\section{DISCUSSION}

In this study, 20 healthy male subjects were evaluated for the effect of treatment with Withania somnifera and placebo on stress induced cardiovascular changes. Physiological parameters have been used as risk factors to predict cardiovascular events. ${ }^{21}$ Accordingly, increased aortic stiffness, enhanced wave reflection, increased systolic pressure and increased central pulse pressure have been identified as independent components of

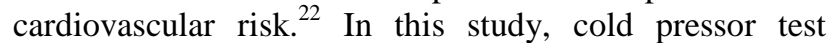
(CPT) was used as a model to produce stress induced cardiovascular changes in healthy subjects.

The cold pressor test which is considered to be a sympatho excitatory maneuver is a simple, non-invasive and validated test of sympathetic activation. ${ }^{23}$ It induces a vascular sympathetic activation and a subsequent increase in blood pressure in healthy subjects. ${ }^{24}$ The principle behind CPT is that sudden and increasingly painful cold stress causes massive discharge of the sympathetic nervous system and release of norepinephrine. This sympathetic discharge triggers responses in the cardiovascular system that includes arteriolar constriction, increased heart rate, and increased cardiac contractility. These responses combine to increase the blood pressure. This is known as the pressor response. ${ }^{25}$ Also, CPT has been shown to cause mild to moderate activation of the HPA axis. $^{26}$ The cold exposure also increases aortic augmentation index (AIx), a measure of wave reflection, leading to augmented central systolic pressure. ${ }^{27}$

Cold pressor test conducted in healthy individuals demonstrated that stress exerted through the cold pressor for a minute stimulated the sympathetic nervous system resulting in accelerated heart rate and elevated blood pressure, both systolic and diastolic, in comparison to those recorded before the foregoing test in all the normotensive volunteers. $^{28}$ In our study, similar observations have been recorded. In our study, there was an increase in aortic pressure, augmentation index, radial and aortic systolic and diastolic BP after CPT. These stress induced changes on cardiovascular parameters were attenuated on treatment with W.somnifera extract. However, treatment with placebo did not show any significant change in response to CPT induced stress.

Augmentation index (AI) determined from either a directly measured or a derived central arterial pressure waveform has been proposed as a measure of aortic stiffness and wave reflection. ${ }^{29}$ Because of the dependence of timing of wave reflection on pulse wave velocity (PWV), reductions in AI after an intervention have been interpreted as evidence of comparable 
reductions in PWV and aortic stiffness. ${ }^{29}$ In our study, W.somnifera significantly attenuated the rise in augmentation index induced by CPT, thus suggesting it's cardio protective effect.

Withania somnifera has been shown to possess cardio protective properties. The pharmacological effects of the roots and leaves of $W$. somnifera are attributed to the presence of Withanolides, a group of steroidal lactones and alkaloids. ${ }^{30,31}$ Experimental studies have demonstrated the hypotensive and bradycardiac effects of Withania alkaloids. Further it was found that the hypotensive effect was due to autonomic ganglion blocking action and depressant action on the higher cerebral centers. The alkaloids produced immediate but short lived cardio-depressant effects and a weak but prolonged cardiotonic effects. ${ }^{32}$

Oxidative stress has been shown to play an important role in the causation of cardiovascular diseases and evidence shows that antioxidant therapy may prove beneficial in combating these problems. ${ }^{33}$ Pre-clinical studies have demonstrated that the cardio protective activity of Withania somnifera is mainly due to its antioxidant and anti-apoptotic activity, both of which constitute the antistress properties. ${ }^{34}$ It increases the level of antioxidant enzymes such as glutathione peroxidase, superoxide dismutase, catalase, creatinine phosphokinase and lactate dehydrogenase. It also inhibits lipid-peroxidation, comparable to vitamin E, a known cardio protective antioxidant. $^{35,36}$ In a study by Thirunavukkarasu et al, W.somnifera was found to possess energy boosting properties in ischaemia-reperfusion compromised heart and it was further recommended to be used as a dietary supplement for cardio protection. ${ }^{37}$ In another study, a polyherbal formulation containing $W$. somnifera has been found cardio protective and antioxidant in isoproterenolinduced ischemic rats. ${ }^{38}$ Apart from the antioxidant effects, W.somnifera has also demonstrated its effect as an adaptogen that works on a nonspecific basis to normalize physiological function, working on the HPA axis and the neuro-endocrine system and thus reducing the stress related changes. ${ }^{39}$ These well-established antioxidant and cardio protective actions of Withania somnifera explain the possible mechanism of $W$. somnifera extract in reducing cardiovascular changes produced by CPT.

\section{CONCLUSION}

The Withania somnifera extract used in the present study showed significant decrease in cold pressor stress test induced changes on aortic wave reflections, suggesting the beneficial effects of this formulation in reducing stress induced cardiovascular changes. However, further clinical studies are warranted to evaluate the beneficial effects of Withania somnifera in patients with cardiovascular and other associated diseases.

\section{ACKNOWLEDGEMENTS}

The authors would like to thank Natreon Inc., USA for providing study medications (Withania somnifera extract and placebo) and literature. Authors thank ICMR (New
Delhi) for extramural grant to develop cold pressor test equipment and Dr. I. V. Sravanthi (Ayurvedic Physician) for her expert advice. Authors also thank Mr. N. Muralidhar for helping in carrying out study related procedures.

Funding: This study was supported by Natreon Inc. USA Conflict of interest: None declared

Ethical approval: The study was approved by the Institutional Ethics Committee

\section{REFERENCES}

1. Bernard C. An introduction to the study of experimental medicine. Transl. HC Greene. New York: Collier; 18651961.

2. Cannon WB. Bodily changes in pain, hunger, fear and rage. $2^{\text {nd }}$ ed. New York: Appleton; 1929.

3. Selye H. The stress of life. New York: McGraw-Hill; 1956.

4. Esch T, Stefano GB, Fricchione GL, Benson H. An overview of stress and its impact in immunological diseases. Modern Aspects of Immunobiology, 2002;2(4):187-92.

5. Negrao AB, Deuster PA, Gold PW, Singh A, Chrousos GP. Individual reactivity and physiology of the stress response. Biomedical Pharmacother. 2000;54:122-8.

6. McCarty R, Gold P. Catecholamines, stress, and disease: a psychobiological Perspective. Psychosomatic Medicine. 1996;58:590-7.

7. Newlin DB, Levenson RW. Cardiovascular responses of individuals with type A behavior pattern and parental coronary heart disease. Journal of Psychosomatic Research. 1982;26:393-402.

8. Marchi ED, Baldassari F, Bononi A, Wieckowski MR, Pinton P. Oxidative stress in cardiovascular diseases and obesity. Role of p66Shc and Protein Kinase C. Oxidative Medicine and Cellular Longevity. 2013: Article ID 564961:11.

9. Dhalla NS, Temsah RM, Netticadan T. Role of oxidative stress in cardiovascular diseases. J Hypertens. 2000;18(6):655-73.

10. Mishra LC, Singh BB, Dagenais S. Scientific basis for the therapeutic use of Withania somnifera (ashwagandha): a review. Altern Med Rev. 2000;5(4):334-46.

11. Uddin Q, Samiulla L, Singh VK, Jamil SS. Phytochemical and pharmacological profile of Withania somnifera dunal: a review. Journal of Applied Pharmaceutical Science. 2012;02 (01):170-5.

12. Mohanty I, Arya DS, Dinda A, Talwar KK, Joshi S, Gupta SK. Mechanisms of cardio protective effect of Withania somnifera in experimentally induced myocardial infarction. Basic Clin Pharmacol Toxicol. 2004;94(4):184-90.

13. Komulainen $\mathrm{S}$, Rintamaki $\mathrm{H}$, Virokannas $\mathrm{H}$, Kiukaanniemi SK. Blood pressure responses to whole-body cold exposure: effect of metoprolol. J Hum Hypertens. 2004;18:905-906. 
14. Korhonen M. Helping inuit clients: cultural relevance and effective counselling. Int J Circumpolar Health. 2004;63:135-8.

15. Bamett PH, Hines EA, Schirger A, Gage RP. Blood pressure and vascular reactivity to the cold pressor test: restudy of 207 subjects 27 years later. JAMA 1963;183:845-8.

16. Reddy KS, Rani PU, Naidu MU, Rao TR. A simple cold pressure technique for the evaluation of analgesic drugs in healthy subjects. Indian $\mathbf{J}$ Pharmacol. 2012;44:571-5.

17. Karamanoglu M, O'Rourke MF, Avolio AP, Kelly RP. An analysis of the relationship between central aortic and peripheral upper limb pressure waves in man. Eur Heart J. 1993;14:160-7.

18. Chen $\mathrm{CH}$, Nevo E, Fetics B, Pak PH, Yin FC, Maughan WL, et al. Estimation of central aortic pressure waveform by mathematical transformation of radial tonometry pressure. Validation of generalized transfer function. Circulation. 1997;95:1827-36.

19. Vlachopoulos C, Hirata K, O'Rourke MF. Effect of caffeine on aortic elastic properties and wave reflection. J Hypertens. 2003;21:563-70.

20. Doonan RJ, Scheffler P, Yu A, Egiziano G, Mutter A, Bacon $S$, et al. Altered arterial stiffness and sub endocardial viability ratio in young healthy light smokers after acute exercise. PLoS One. 2011;6:26151.

21. Lin WH, Zhang $\mathrm{H}$, Zhang YT. Investigation on cardiovascular risk prediction using physiological parameters. Computational and Mathematical Methods in Medicine. 2013;Article ID 272691:21.

22. Mitchell GF. Arterial stiffness and wave reflection: biomarkers of cardiovascular risk. Artery Res. 2009;3:56-64.

23. Lafleche AB, Pannier BM, Lalous B, Safar ME. Arterial response during cold pressor test in borderline hypertension. Am J Physiol.1998;275:409-15.

24. Mourot L, Bouhaddi M, Regnard J. Effects of the cold pressor test on cardiac autonomic control in normal subjects. Physiol Res. 2009;58(1):83-91.

25. Silverthorn DU, Michael J. Cold stress and the cold pressor test. Advances in Physiology Education Published. 2013;37(1|):93-6.

26. Schwabe L, Haddad L, Schachinger H. HPA axis activation by a socially evaluated cold-pressor test. Psycho neuro endocrinology. 2008;33:890-5.

27. Edwards DG, Roy MS, Prasad RY. Wave reflection augments central systolic and pulse pressures during facial cooling. Am J Physiol Heart Circ Physiol 2008;294:2535-9.

28. Tapas P, Regmi P, Adhikari P, Roychowdhury P. Cold pressor test as a predictor of hypertension. $\mathrm{J}$ Tehran Univ Heart Cent. 2009;3:177-80.

29. Mitchell GF, Lacourcière Y, Arnold JMO, Dunlap ME, Conlin PR, Izzo JL, et al. Changes in aortic stiffness and augmentation index after acute converting enzyme or vasopeptidase inhibition. Hypertension. 2005;46:1111-7.

30. Budhiraja RD, Sudhir SJ. Sci Ind Res. 1987;42:488-91.

31. Glotter E, Kirson I, Abraham A, Lavie D. Tetrahedron. 1973;29:1353-64.

32. Malhotra CL, Das PK, Dhalla NS, Prasad K. Studies on Withania ashwagandha, kaul III. The effect of total alkaloids on the cardiovascular system and respiration. Indian J Med Res. 1981;49:448-60.

33. Dhalla NS, Temsah RM, Netticadan T. Role of oxidative stress in cardiovascular diseases. J Hypertens. 2000;18(6):655-73.

34. Alam N, Hossain M, Khalil MI, Moniruzzaman M, Sulaiman SA, Gan SH, et al. Recent advances in elucidating the biological properties of Withania somnifera and its potential role in health benefits. Phytochem Rev. 2012;11:97-112.

35. Mohanty I, Arya DS, Dinda A, Talwar KK, Joshi S, Gupta SK. Mechanisms of cardioprotective effect of Withania somnifera in experimentally induced myocardial infarction. Basic Clin. Pharmacol. Toxicol. 2004;94:184-90.

36. Gupta SK, Mohanty I, Talwar KK, Dinda A, Joshi S, Bansal P, et al. Cardioprotection from ischemia and reperfusion injury by Withania somnifera: a hemodynamic, biochemical and histopathological assessment. Mol. Cell Biochem. 2004;260:39-47.

37. Thirunavukkarasu M, Penumathsa S, Juhasz B, Zhan L, Bagchi M, Yasmin $\mathrm{T}$, et al. Enhanced cardiovascular function and energy level by a novel chromium (III)-supplement. Biofactors. 2006;27:53-67.

38. Prince PSM, Selvaraju S, Devika PT, Vaithianathan. Cardioprotective effect of 'Marutham' a polyherbal formulation on isoproterenol induced myocardial infarction in Wistar rats. Fitoterapia. 2008;79:433-8.

39. Sharma V, Sharma S, Pracheta, Paliwal R. Withania somnifera: a rejuvenating ayurvedic medicinal herb for the treatment of various human ailments. IJPRIF. 2011;3(1):187-92.

Cite this article as: Pilli R, Koilagundla N, Ramakanth GSH, Pingali U. Evaluation of effect of highly standardized aqueous extract of roots and leaves of Withania somnifera on cold pressor test induced cardiovascular changes in healthy human subjects. Int J Basic Clin Pharmacol 2016;5:873-8. 